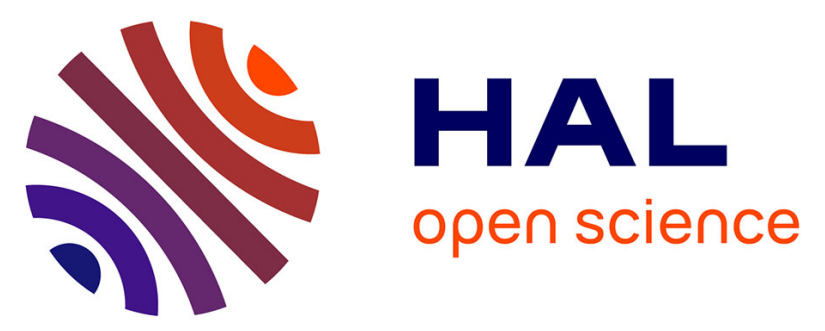

\title{
Experimental procedure to characterize the mode I dynamic fracture toughness of advanced epoxy resins
}

\author{
Vincent Joudon, G. Portemont, Franck Lauro, Bruno Bennani
}

\section{To cite this version:}

Vincent Joudon, G. Portemont, Franck Lauro, Bruno Bennani. Experimental procedure to characterize the mode I dynamic fracture toughness of advanced epoxy resins. 4th International Conference of Impact Loading on Lightweight Structures (ICILLS 2014), Jan 2014, CAP TOWN, South Africa. pp.166 - 177, 10.1016/j.engfracmech.2014.05.010 . hal-01077326

\section{HAL Id: hal-01077326 \\ https://hal.science/hal-01077326}

Submitted on 24 Oct 2014

HAL is a multi-disciplinary open access archive for the deposit and dissemination of scientific research documents, whether they are published or not. The documents may come from teaching and research institutions in France or abroad, or from public or private research centers.
L'archive ouverte pluridisciplinaire HAL, est destinée au dépôt et à la diffusion de documents scientifiques de niveau recherche, publiés ou non, émanant des établissements d'enseignement et de recherche français ou étrangers, des laboratoires publics ou privés. 


\title{
Experimental procedure to characterize the mode I dynamic fracture toughness of epoxy resins.
}

\author{
V. Joudon ${ }^{1,2^{*}}$, G. Portemont ${ }^{1}$, F. Lauro ${ }^{2}$, B. Bennani ${ }^{2}$ \\ ${ }^{1}$ The French Aerospace Lab (ONERA), Lille, France \\ ${ }^{2}$ LAMIH (UMR CNRS 8201), Université de Valenciennes, Valenciennes, France \\ *Corresponding author (email: vincent.joudon@onera.fr)
}

\begin{abstract}
Epoxy resins are widely used in Carbon Fiber Reinforced Polymers (CFRPs) for the aeronautical industry. They must ensure cohesion in most of the structural composite parts incorporated into the modern manufactured aircrafts. So fracture properties of epoxy resins are essential features to resist critical decohesions in case of impact. Surprisingly however, there are few experimental studies dedicated to the dynamic fracture of these thermoset polymers. Therefore, this research aims at developing an experimental procedure to characterize the dynamic fracture toughness of epoxy resins during propagation. Since glassy polymers exhibit viscous fracture, the crack speed å is known for influencing the toughness of these materials. Then a strain gage method is proposed to determine the

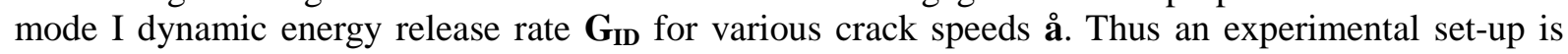
defined to simultaneously implement strain gage measurement and high speed cinematography. Finally, preliminary results are briefly reported to demonstrate the method validity.
\end{abstract}

Keywords: Experimental, Dynamic Toughness, Epoxy Resin, Reinforced Polymer, Cohesive Model.

\section{Introduction}

Impact loadings on laminated composite materials may damage the interlaminar phase and initiate the delamination process. This large decohesion critically compromises the integrity of light weight structures made of CFRPs. The material constituting the interlaminar phase must ensure overall cohesion and resist crack propagation. Thermoset epoxy resins are incorporated in most CFRPs since they present good mechanical properties while exhibiting a satisfactory damage tolerance. Moreover, epoxy resins are classically reinforced with embedded thermoplastic nodules that improve their fracture toughness. This material property is characterized by the energy release rate $\mathbf{G}$ which stands for the energy per unit area dissipated to form new crack surfaces. For a mode I crack opening, the critical energy release rate $\mathbf{G}_{\mathbf{I C}}$ refers to the initiation, and the dynamic energy release rate $\mathbf{G}_{\mathbf{I D}}$ is dedicated to the propagation stage. The experimental determination of $\mathbf{G}_{\mathbf{I D}}$ is essential to numerically simulate dynamic propagation of a crack in the interlaminar phase with Cohesive Zone Models (CZMs). However, most of the experimental researches on epoxy resins only identify the initiation toughness from quasi-static tests preventing CZMs to finely describe dynamic crack propagation.

As glassy polymers, epoxy resins fracture in a cohesive way according to the viscous crazing process described by Kramer and Berger [1]. The extension of crack surface involves successively alignment, stretching and breakdown of the molecular chains. Each stage of the crazing process influences the fracture toughness. As a consequence, the mode I dynamic energy release rate $\mathbf{G}_{\mathbf{I D}}$ for epoxy resins is expected to be sensitive to dynamic conditions. In experimental studies on crack propagation in polymethylmethacrylate (PMMA), some authors have reported a strong variation of the fracture toughness with the crack speed parameter å $[2,3]$. Further research on polycarbonate (PC) and PMMA demonstrated that glassy polymers can also exhibit localized heating surrounding a running crack tip $[3,4]$. This increase in the temperature $\mathbf{T}_{\mathbf{f}}$ of the craze zone induces evolution in the material toughness. Therefore, the final purpose of the present research is the definition of an experimental procedure to characterize the dynamic law $\mathbf{G}_{\mathbf{I D}}\left(\stackrel{\mathrm{a}}{,} \mathbf{T}_{\mathbf{f}}\right)$ for epoxy resins. This article focuses on the experimental determination of the mechanical quantities $\mathbf{G}_{\mathbf{I D}}$ and $\mathbf{a}$. 


\section{Experimental determination of $\mathbf{G}_{\mathrm{ID}}$}

Linear elastic behavior is assumed in the bulk material because glassy polymers only develop small scale plasticity in the vicinity of the crack tip [3]. A local analysis of the asymptotic mechanical fields is used to measure the mode I dynamic stress intensity factor $\mathbf{K}_{\mathbf{I D}}$ related to a crack propagating at constant speed å. The strain gage technique depicted by Khanna and Shukla [5] is implemented as it fits dynamic loadings. This method consists in bounding a strain gage at a distance $\mathbf{y}_{\mathbf{G}}$ close to the crack path (Figure 1) at an angle $\boldsymbol{\alpha}$ verifying the relation Eq. 1 for prevailing plane strain condition,

$$
\cos (2 \alpha)=-\kappa=-(1-2 \nu) .
$$

The obtuse angle $\boldsymbol{\alpha}$ is then selected according to the Poisson's ratio $\mathbf{v}$ and the distance $\mathbf{y}_{\mathbf{G}}$ must be short enough to ensure that the strain gage is located in the singularity dominated zone. In such a case, a peak strain $\left(\varepsilon_{\mathbf{x} 2}{ }^{\mathbf{G}}\right)_{\mathbf{p}}$ is registered when the crack passes below the strain gage, corresponding to $\boldsymbol{\theta}=\mathbf{9 0}^{\circ}$ (Figures $1 \& 2$ ). Then, the two parameter model detailed in Eq. 2 is used to evaluate the mode I dynamic stress intensity factor $\mathbf{K}_{\mathbf{I D}}$,

$$
K_{I D}=\mu \cdot\left(\epsilon_{x_{2}}^{G}\right)_{p} \cdot \frac{1}{\sqrt{y_{G}}} \cdot\left[A(\dot{a}, \alpha)+k_{d} \cdot y_{G} \cdot B(\dot{a}, \alpha)\right]^{-1} .
$$

Dimensionless coefficients $(\mathbf{A}, \mathbf{B})$ are material dependent, function of the crack propagation speed å and the angle $\boldsymbol{\alpha}$. The material parameter $\boldsymbol{\mu}$ is the shear modulus. It is worth noting that material parameters in this analysis are quasi-static values. The non-singular coefficient $\mathbf{k}_{\mathbf{d}}$ is identified using the characteristic time $\Delta \mathbf{t}_{3 / 4}$ defined in Figure 2 according to the procedure described in Sanford and al. [6]. The mode I dynamic energy release rate $\mathbf{G}_{\mathbf{I D}}$ is then derived from $\mathbf{K}_{\mathbf{I D}}$ by the Freund relation [7] which is the dynamic equivalent of the well-known Irwin formula,

$$
G_{I D}=f(\dot{a}) \cdot K_{I D}^{2} \text {. }
$$

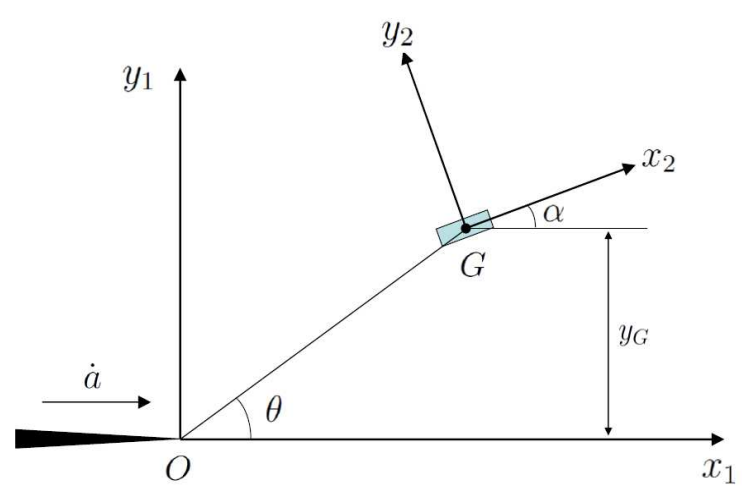

Figure 1 : Description of the strain gage position with respect to the crack tip.

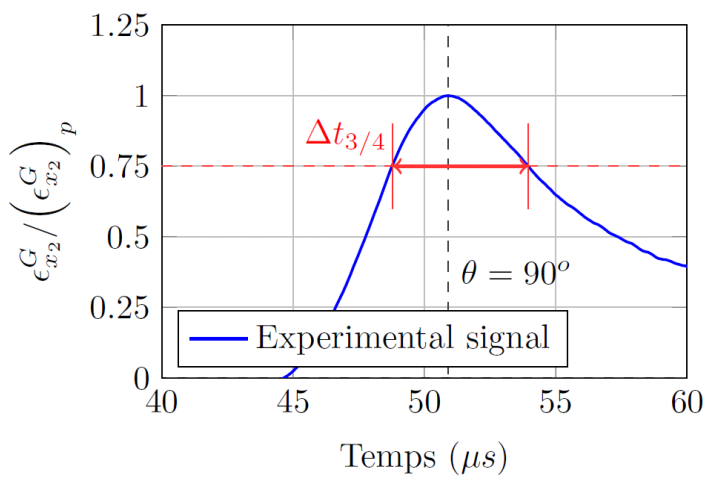

Figure 2 : Peak strain registered by the strain gage oriented at the obtuse angle $\alpha$ verifying Eq. 1.

\section{Experimental set-up}

A three point bending test was chosen to fracture Single Edge Notched Beam (SENB) specimens (Figure 4). Therefore, thick test samples of pure epoxy resin were manufactured (dimensions: $90 \mathrm{~mm} \mathrm{x}$ $20 \mathrm{~mm} \times 8 \mathrm{~mm}$ ). For this purpose, hundreds of plies of epoxy prepreg were successively stacked and several vacuum debulking had to be applied to ensure removal of air trapped during the lay-up operation. Autoclave curing of the laminated plate was performed according to the typical cure cycle specified by the manufacturer for thick structures. This cycle is optimized to eliminate remaining air 
inclusions and provide homogeneous plates. So the resulting specimens are suitable to determine the material fracture properties.

The three point bending test presents the advantage of exhibit symmetric fracture with good repeatability. Indeed, a straight propagation is essential to perform valid mechanical analysis exposed previously and anticipate the location of sensors close enough to the crack. For preliminary experiments on SENB epoxy specimens, two strain gages of different grid size were bounded respectively on each side of the crack path in a symmetric way as illustrated in Figure 3. They were fixed on the same axis perpendicular to the crack surface so as to provide $\mathbf{G}_{\mathbf{I D}}$ for the same time of fracture. The ratio $\mathbf{a} / \mathbf{w}$ was set to 0.40 to limit influence of the specimen boundaries. In addition, the crack propagation speed å was evaluated by high speed cinematography.

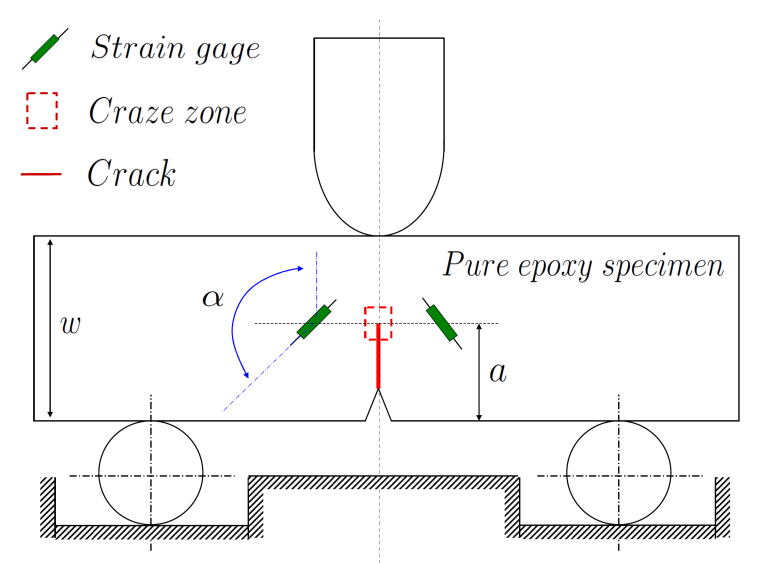

Figure 3 : Diagram of the experimental set-up with specimen instrumented.

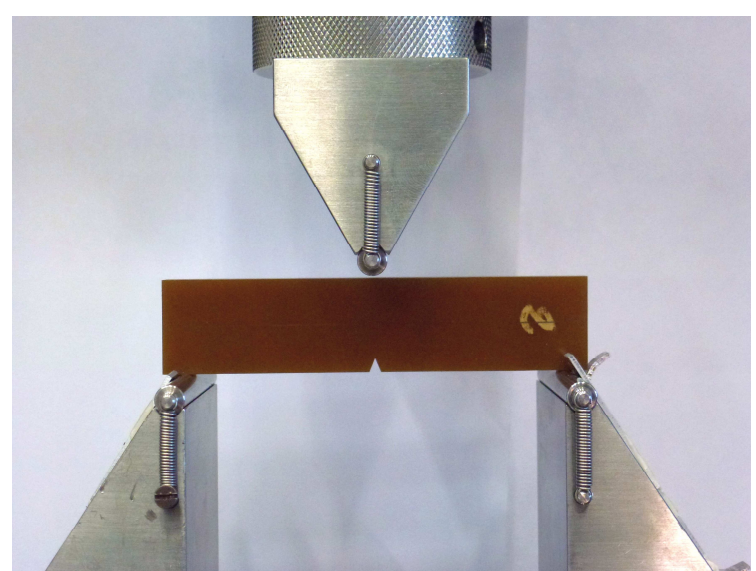

Figure 4 : Picture of the experimental set-up without instrumentation.

\section{Preliminary results}

Preliminary experiments exhibited quasi-brittle fractures and the crack propagated in a straight direction, verifying essential assumptions of the mechanical analysis. Moreover, the peak strain due to the singularity dominated zone was actually recorded when the crack tip passed below the gage.

For the particular experiment summarized in Table 1, the distance to the crack path and the grid length varied with the considered sensor configuration. However the shapes of the normalized peak strain signals represented in Figure 5 are quite identical, except for the time $\Delta \mathbf{t}_{3 / 4}$ which is greater for gage 2 since it increases with the distance $\mathbf{y}_{\mathbf{G}}$. This demonstrates that the singular strain field was similarly captured on each side of the crack path in both tested strain gage configurations with limited influence of the gage size on the characteristic time $\Delta \mathbf{t}_{3 / 4}$.

In addition, each recorded signal was post processed following the procedure described previously to identify the dynamic stress intensity factor $\mathbf{K}_{\mathrm{ID}}$ and the dynamic energy release rate $\mathbf{G}_{\mathrm{ID}}$ normalized with the corresponding initiation values $\mathbf{K}_{\mathbf{I C}}$ and $\mathbf{G}_{\mathbf{I C}}$. Although strain gage configurations were different, the mechanical analysis gives very similar values reported in Table 1 . These converging results in the determination of $\mathbf{K}_{\mathbf{I D}}$ and $\mathbf{G}_{\mathrm{ID}}$ prove that the two parameter model depicted in Eq. 2 is able to describe the singularity strain field around the crack tip with sufficient accuracy for this experimental set-up using one of the tested strain gage configurations. Finally, the proposed procedure is validated for strain gage of grid length under $0.60 \mathrm{~mm}$, bounded at a distance closer to $1.50 \mathrm{~mm}$ from the crack path. 


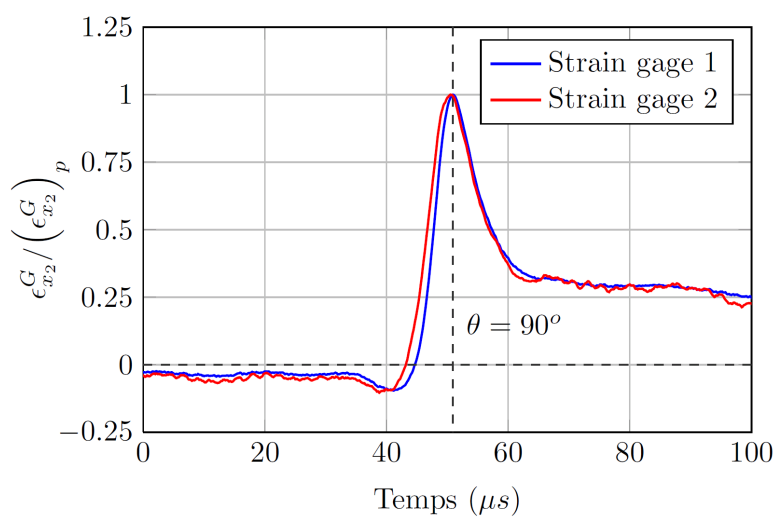

Figure 5 : Strain gage signals recorded for the same experiment with a/w set to 0,40 .
Table 1 : Experimental results referring to signals reported in Figure 5.

\begin{tabular}{|c|c|c|}
\hline & Gage 1 & Gage 2 \\
\hline Gage length & $0.38 \mathrm{~mm}$ & $0.60 \mathrm{~mm}$ \\
\hline $\mathbf{a}$ & \multicolumn{2}{|c|}{$255 \mathrm{~m} / \mathrm{s}$} \\
\hline $\mathbf{y}_{\mathbf{G}}$ & $1.29 \mathrm{~mm}$ & $1.50 \mathrm{~mm}$ \\
\hline$\Delta \mathbf{t}_{\mathbf{3} / \mathbf{4}}$ & $5.2 \mu \mathrm{s}$ & $5.7 \mu \mathrm{s}$ \\
\hline $\mathbf{K}_{\mathbf{I D}} / \mathbf{K}_{\mathbf{I C}}$ & $\mathbf{0 . 8 8}$ & $\mathbf{0 . 9 1}$ \\
\hline $\mathbf{G}_{\mathbf{I D}} / \mathbf{G}_{\mathbf{I C}}$ & $\mathbf{0 . 6 2}$ & $\mathbf{0 . 6 6}$ \\
\hline
\end{tabular}

\section{Conclusion}

In this research, an experimental procedure was developed to characterize the dynamic fracture toughness of epoxy resins. A strain gage technique associated to high speed cinematography was detailed for simultaneous measurements of the mode I dynamic energy release rate $\mathbf{G}_{\mathbf{I D}}$ and the crack propagation speed å during fracture. Preliminary experimental results concerning the determination of $\mathbf{G}_{\text {ID }}$ were reported for different strain gage configurations. Experiments exhibited straight propagation paths and the analysis of the respective peak strain signals gave very similar results. These converging $\mathbf{G}_{\text {ID }}$ values validated the proposed procedure for the tested strain gage configurations.

\section{Acknowledgements}

The authors gratefully acknowledge the Nord-Pas de Calais Region for its financial support. The FEDER and the French ministry of Defense and Research are also gratefully acknowledged for the funding of equipments to the mechanical test laboratory in the framework of the CPER CISIT.

\section{References}

[1] E.J. Kramer and L.L. Berger, Fundamental processes of craze growth and fracture, Advances in Polymer Science, Vol.91/92, pp.1-68, 1990.

[2] F. Zhou, J.-F. Molinari and T. Shioya, A rate-dependent cohesive model for simulating dynamic crack propagation in brittle materials, Engineering Fracture Mechanics, Vol.72, pp.1383-1410, 2005.

[3] T.W. Bjerke and J. Lambros, Theorical development and experimental validation of a thermally dissipative cohesive zone model for dynamic fracture of amorphous polymers, Journal of the Mechanics and Physics of Solids, Vol.51, pp.1147-1170, 2003.

[4] D. Rittel, Experimental investigation of transient thermoelastic effects in dynamic fracture, International Journal of Solids and Structures, Vol.35, No.22, pp.2959-2973, 1998.

[5] S.K. Khanna and A. Shukla, On the use of strain gages in dynamic fracture mechanics, Engineering Fracture Mechanics, Vol.51, No.6, pp.933-948, 1995.

[6] R.J. Sanford, J.W. Dally and J.R. Berger, An improved strain gauge method for measuring KID for a propagating crack, Journal of strain analysis, Vol.25, No.3, pp.177-183, 1990.

[7] L.B. Freund, Dynamic fracture mechanics, Cambridge University Press, 1990. 